of the astragalus, calcis, and the soft parts covering them, is thus removed. The articular surfaces of the tibia and fibula with the malleoli are now sawn off, as well as those of the cuboid and scaphoid bones. (Fig. 2.) The anterior

F'IG. 2.
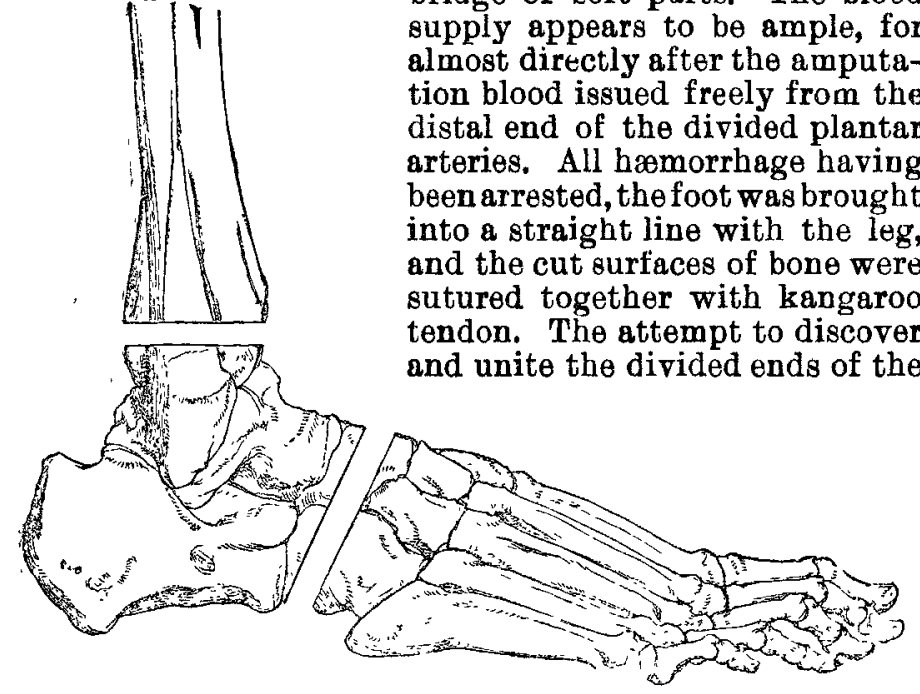

Line of section of the bones.

posterior tibial nerve failed on account of the sodden condition of the soft parts. Suitable dressings and a plaster-ofParis splint were applied, the toes being brought into a position of complete dorsal flexion.

I need not detail the after-treatment; the boy made an excellent recovery, and a firm bony union eventually took

$$
\text { FIG, } 3 .
$$

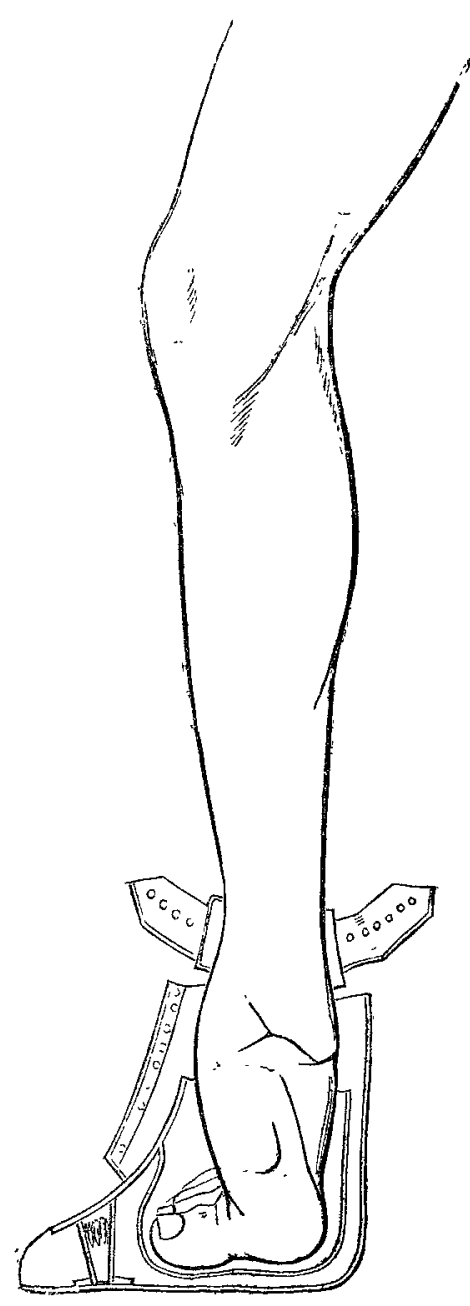

Convenient form of boot applied to the stump.
Fig. 4.

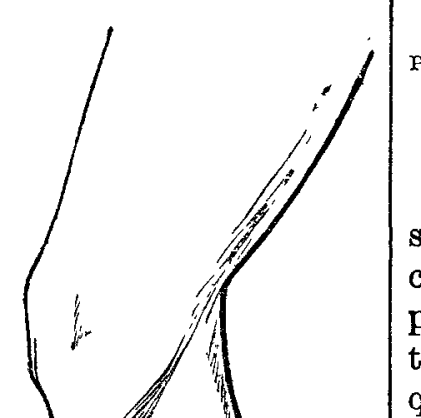

left foot appears to be perfect, showing that the divided nerve ends have become united. The toes are mobile. I regard such a result as this, obtained under very unfavourable circumstances, an exceedingly satisfactory proof of the utility of the operation. Wladimiroff of Kasan, in 1872 appears to have been the first to perform the operation; but Mikulicz first published an account of it in Lavgenbeck's Archiv, 1881. The functional result, as I think this case will show, is an admirable one. An artificial pes equinus is procured, the object being to preserve the toes and metatarsal bones, which are sacrificed in other amputations of the foot. These are brought into a straight line with the leg, and the toes bent at a right angle, so that the patient waiks on the ends of the metatarsal bones covered by the thick pads of tissue which invest, them; a broader surface of support is provided than is afforded after either Syme's or Pirogoff's amputations, and there is some elasticity of foot left. (Fig.4.) In ordinary cases the limb will be longer by nearly an inch, which can be readily compensated for by a thicker sole to the other boot. As regards indications, it may be at once conceded that the operation will prove better adapted to cases of injury, gunshot injury more especially, than for those of disease. My experience of this case, however, would tempt me to adopt the procedure again in any case where the bones of the heel and the soft parts covering them were extensively damaged or diseased, the anterior half of the foot remaining healthy.

[The patient was exhibited to the Fellows. He walked up and down the room, both with and without his boot, with great ease and evident satisfaction to himself. The union is quite solid, and he now attends to his daily work without any inconvenience.]

\section{CLINICAL EXPERIENCE OF SOME OF THE MORE RECENTLY INTRODUCED DRUGS.}

BY THOMAS OLIVER, M.D., M.R.C.P. LOND.,

PHYSICIAN TO THE ROYAL DNTLRMARX, AND LECTURER ON PHYSTOLOGY IN THE UNIVERSITY OF DUREAM COLLEGE OF MEDICINE, NEWCASTLE-UPON-TYNE.

I ventune briefly to place before the profession the results of my experience of some of the newer drugs. We cannot but admit that within the last few years very important additions have been made to our already long list of therapeutic agents, and that, whilst many of them have quite fulfilled all that was expected of them, others have just as much failed to do so, and as a consequence are being discarded.

Jambul was recommended a few months ago as a cure for diabetes mellitus. The powdered seed was credited with having the property of diminishing the secretion of urine and of arresting the formation of sugar. Four patients suffering from diabetes have been treated by me with powdered jambul. I began with five-grain doses thrice daily, and gradually increased the dose to fifteen grains. Two of the patients died, both from coma ; the other two are still alive, but are no longer taking the drug. It cannot be said that any one of them received the slightest benefit. The aaily amount of sugar passed out of the system was not diminished, thirst was not in any way abated, the daily discharge of urine remained as before, and the weight of the body was not increased. In one of the cases, strange to say, two days after taking the jambul the daily elimination of sugar fell from 4000 to 600 grains, but on the following and succeeding days the amount rose, and by degrees increased until it reached the sum eliminated before the drug was administered. Arterial tension was not in any way affected by the drug.

Salol, a compound of ealicylic and carbolic acids, has been recommended as an antifebrile agent. In my hands it has not had any effect in reducing the high temperature of phthisis; nor did it, as one would have expected from the nature of the ingredients of which it is composed, diminish the amount of pus secreted by inflamed surfaces, as occurs in pyelitis and cystitis. In these latter ailments the drug was not at all well borne. I have seen discolouration of the urine produced by it, but I have never met with any bad effects, as in carbolic acid poisoning. It is as an antirheumatic, however, that salol has also been recommended, and $m y$ experience of it in cases of rheumatic fever is ex-

place. Sensibility began to return in the sole of the foot in about a month, and this gradually became more complete. In December the boy returned to the hospital to be fitted for the boot he now wears. (Fig. 3.) He can stand or walk with ease and comfort. The left limb is half an inch longer than the right. (Fig. 4.) The sensibility of the 
tremely favourable. Where the temperature in such has been high, and has not been reduced for more than a day or two by sodium salicylate in fifteen-grain doses given every few hours, and where, owing to the anæmia which had been developed and the great depression caused by the sodium salt-symptoms which forbade an extended use of the drug, - salol has with me not only been followed by a reduction of temperature and pulse, both of which have ever afterwards remained at the normal, but by a feeling of comfort and a sense of well-being such as patients experience when, having passed through a serious illness, they are conscious of having become convalescent. Salol has not perceptibly diminished the tendency to endocarditis in rheumatic fever.

For the earliest notice of Collinsonia Canadensis-stone or knob root-we are indebted to Dr. Shoemaker of Philadelphia. Like nearly all the new drugs, it is recommended, but not by him, for nearly every disease-for more, at any rate, than it can ever be expected to accomplish ; but so far as its curative effects upon the genito-urinary passages are concerned, I can speak of it in the highest terms. It is spoken of as a sedative and an antispasmodic, as relaxing the spasm of the ureters, and therefore allowing of the escape of renal calculi with greater ease and less pain. It is also recommended as a remedy in acute cystitis. A few months ago Dr. Anderson of Loftus-in-Clevedale sent me a boy, aged twelve, who for some time previously had been the subject of excessively frequent micturition, passing large quantities of pus (sometimes with, sometimes without blood) in the urine, and who had complained much of suprapubic pain, increased by pressure, and also pain at the point of the penis. He was an intelligent lad, and could tell to the week when hisillness began, the first symptom being increased frequency of micturition. When admitted, his urine was alkaline, had a most disagreeable odour, and, on standing, the pus was seen to reach half-way up the glass. As his symptoms pointed to the presence of stone in the bladder, he was sounded by Dr. Anderson, but no calculus was detected. Shortly after this-his condition meanwhile becoming worse - he was sent to Newcastle. For a week or ten days he was treated by the ordinary remedies hitherto employed in the treatment of cystitis, suppositories of belladonna, too, being employed night and morning, but without the least improvement. Thinking that there might be a stone in his bladder, I had the patient chloroformed and examined for stone by my surgical colleagues, Dr. Hume and Mr. Dodd. No stone was found. Again for a fortnight the ordinary remedies were employed, but as the boy's condition was gradually becoming worse I put him upon the liquid extract of collinsonia in fifteen-minim doses thrice daily. Within ten days he felt much more comfortable; he could now retain his urine longer, and in this way his night's rest was not so much broken. By degrees the height to which the pus reached in the glass was seen to be getting less. The pus, and with it the albumen, gradually diminished, until within twenty-one days from taking the collinsonia all the pus had disappeared and the patient could go from four to six hours without requiring to empty his bladder. His night's rest was now no longer disturbed, his pains had all gone, the urine had again become clear, appetite had improved, flesh had been put on, and in this condition he went home. In a letter from Dr. Anderson, received a few days ago, I am told that several weeks afterwards the patient had a slight return of his symptoms, but they disappeared on again resorting to the collinsonia. Now here was a case which baffled treatment by all the drugs generally used in the treatment of cystitis, so that we cannot but regard the good and speedy result obtained as due to the collinsonia. In another case, that of a lad sent to me by Dr. Mackay of Esh, in whom there was pyelitis due to iujury, and in whom every week or ten days the ureter evidently became blocked judging from the suppression of urine, with extreme pain and fulness in the region of the left kidney, and rigors, the pain greatly disappeared after taking collinsonia, and the urine was frequently clear of pus, and only once in eight weeks had the ureter become blocked; the symptoms, but without the rigors, have from time to time recurred. In other two cases of pyelitis I have tried collinsonia; but beyond making one of the patients feel a little more comfortable, it cannot be said that the amount of pus has diminished. The best results are obtained in the treatment of cystitis.

Antipyrin is certainly a drug which has a wonderful power in reducing high temperatures, and that quickly too. In some cases of typhoid fever I bave known it reduce the temperature within two hours from $106^{\circ}$ to $101^{\circ}$. It is in the treatment of typhoid fever that its best results as a heatreducing agent have been obtained. Here a high temperature may become a source of danger; in patients thus affected tissue metabolism is exaggerated, and, as the functions of the various excretory organs are deranged, the increased amount of waste material accumulates in the blood and tends further to endanger life. To reduce the bigh temperature in such is surely an object we should strive for, so long as that reduction is neither too hasty nor too great. It is these very things, in fact, that have been claimed for the cold-bath treatment of fever. Now, in antipyrin, carefully and judiciously employed, we bave a drug which gives the same result without removing the patient from his bed. It is recommended by some writers to be given in doses varying from fifteen to thirty grains every few hours. Here a word of caution must be expressed, to young practitioners particularly. To my knowledge, the pushing of antipyrin in fifteen-grain doses is not without danger. The drug requires to be watched, for not only has the temperature in some cases been rapidly reduced below the normal, but in some collapse has taken place-collapse not of a slight, but of a threatening, character, and requiring to be met by the free administration of stimulants. After the first two doses of fifteen grains, I seldom give it in larger doses than from seven to ten grains, when it has to be taken regularly. Since the recommendation of antipyrin by M. Germain Sée in the treatment of migraine and neuralgia, and in the treatment of the ill-defined and so-called ovarian pains in women in whom no special pelvic or uterine disease can be detected, antipyrin bas in my hande proved itself to be a most useful and serviceable drug. In a case of chorea, too, with mitral stenosis-a young lady of eighteen,-and where arsenic, chloral, bromide, and other medicines failed, antipyrin, given in seven-grain doses thrice daily, has been followed by disappearance of the disorderly movements, and in a case of locomotor ataxy the burning pains in the soles of the feet subsided under its administration. I have had no experience of antipyrin as a hæmostatic in typhoid fever. Given for neuralgia, I have seen a herpetic eruption follow the second dose.

Ammonium or Calcium Sulphide.-Some months ago I noticed in one of the medical journals the results of experiments upon animals subjected to the influence of sulphuretted hydrogen in the manner recommended by Bergeon in the treatment of phthisis. Into the rectumas suggested by Bergeon for phthisical patients-were in jected large quantities of sulphuretted hydrogen in water, and after repeated injections the rabbits died. It was found post mortem that glycogen had disappeared entirely from the liver; repeated washings out of the liver failed to give any indication of the presence of glycogen. The absence of glycogen post mortem in the liver of animals thus experimented upon was so constant that to the observers the two circumstances seemed to stand in a causal relationship to each other. If, therefore, it was the case that the passing into the blood of large quantities of sulphuretted hydrogen destroyed entirely the glycogenic function of the liver in health, it occurred to $\mathrm{me}$ that possibly it might restrain its increased functional activity in diabetes. Three cases of diabetes were accordingly treated, each patient receiving three minims of ammonium sulphide, this being extremely volatile. In one of the cases of diabetes, albumen, which was present in the urine, disappeared, and has never returned. For a few weeks the daily a mount of sugar fell onethird, but the quantity of urine remained the same. The other two patients felt better whilst taking the drug-one of them even gaining several pounds in weight. It is to be noted, however, that the special diabetic diet begun before the treatment was adopted was continued, and this could not be without an influence for good. After taking the drug for four or five weeks, it was found that in each case the digestive organs gradually became leranged, and a most complete distaste for food was established, accompanied by an increase in the feeling of lassitude so frequently complained of by diabetics, that this line of treatment had to be abandoned. Calcium sulphide is being tried instead, as it can be taken for a longer period without giving rise to intestinal disturbance.

Hydrastis Canadensis, or the Golden Seal, is, of all the more recently introduced drugs, one which, with a larger experience, increases in favour daily. It was the knowledge which Professor Schatz of Rostock had of the efficacy of hydrastis canadensis in inducing strong peristaltic contractions of the intestine that led him to employ it as a 
uterine tonic. So successful has Schatz been in the treatment of diseases of the uterus and its appendages which are attended by considerable losses of blood, that since employing this drug in the treatment of these cases there has not been in his district, it is said, the necessity to have recourse to surgical proceedings so frequently as formerly. Hydrastis is recommended for all forms of chronic metritis, for inflammations invading the tissues around and in the wall of the iterus, for ovaritis, and for uterine fibromata, the growth of the latter, it is maintained, being not only arrested, but in many cases they have been found to undergo retrogression. Hydrastis certainly does restrain the flow of blood in myofibromata, but it is in cases of menorrhagia whera the loss of blood depends upon a para- or perimetritis that its efficacy, in my opinion, is most marked. It not only relieves ovarian pain, but it has checked uterine hæmorrhage in cases where there has been such evidence of inflammation outside and immediately around the uterus that intra-uterine medication could not have been attempted. The drug has, in my hands, had little or no effect upon uterine hæmorrhage dependent upon mucous polypi. I regard hydrastis canadensis as a most useful and valuable addition to our already large list of uterine remedies. It soothes ovarian pain, acute or chronic, and checks the bleedings of the latter; it checks the bleeding of endometritis, and relieves that unpleasant pain which prevents the woman thus affected from either sitting or walking; it relieves, and in many cases has arrested, the hæmorrhage due to puerperal metritis and chronic peritonitis; and in many instances it has relieved the headache so frequently complained of by women who are the subjects of chronic inflammatory affections in and around the uterus and ovaries.

Salix Nigra, or the Pussy Willow, is reported upon by Mr. Pain in the Transactions of the Texas State Medical Association as a successful agent in the treatment of ovarian hyperæsthesia, uterine neuralgia, and spermatorrboea. $\mathrm{He}$ regards it as a sexual sedative, similar to bromide, but without its depressing effects. Dr. Hutchison of Glasgow speaks well of the drug, and Mr. Hurry Fenwick found it of much service in the treatment of gonorrhoes and gleet. In my hands it has not been of any value in the treatment of spermatorrhos, but in the treatment of ovarian pain due to pelvic peritonitis, or an associated metritis, or in the chronic ovarialgia of gonorrhoeal infection, relief has followed its administration in some, whilst in others the ovarian pain has completely disappeared. In cases of pelvic peritonitis, where there has been ovarian pain and uterine hæmorrhage, the combination of hydrastis canadensis and salix nigra has been of such signal service that I cannot press too hard upon the members of our profession when I ask them to give it a trial. In the highly nervous condition into which some women are so frequently thrown soon after the climacteric period-in whom, in short, hyperæsthesia rather than anæsthesia, excitability rather than atony, of the nerrous system is present-salix nigra and hydrastis canadensis have answered well in combination.

\section{THE MUD-BATHS OF MARIENBAD.}

\section{By E. HENRY KISCH, M.D.,}

PROTESSOR IN THE UNIVRRSTTY OF PRAGUE; CONSULTING PHYSICIAN AT MARIENBAD, BOFEMIA.

THE mud-baths (Moorbaeder) of Marienbad are much less known than the saline-alkaline waters, especially the Kreuzbrunnen, to which Marienbad owes its celebrity; but they are the most important baths in Bohemia. In the neighbourhood of Marienbad are found two kinds of earth (Mineralmoor), which are applied to medical purposes; the "old mud" and the "new mud." The mud consists of decomposed mineral and vegetable substances, of residues of plants, vegetable earth and ulmic acid, of resins, siliceous earth and clay, of phosphate, of protoxide of iron, sulphate of iron, chloride of sodium, sulphates of carbonic acid, and sulphuric and formic acid. Springs of mineral water, and such as give out carbonic acid and sulphuretted hydrogen gas, rise from the bog in great numbers, and have without doubt contributed much to the peculiar decomposition of the plants. The "new mud," which is the stronger of the two earths, fresh from the bog, is of a brown colour, and shows incrustations and lumps of sulphuret of iron; when exposed to the air it rapidly turns black, and if kept dry forms a white crystalline powder on its surface. Exposed to the influence of the air and water, most of its constituents are oxidised, and the most essential result of this process consists in the formation, out of insoluble mineral and organic matter, of substances capable of solution and of certain volatile acids. The bisulphuret of iron is changed more or less completely into soluble sulphate of protoxide of iron. The new Marienbad mud considerably exceeds all the muds hitherto analysed, including that of Franzeasbad, in the amount of iron contained.

The physiological effect s noticed when one enters a mudbath are, according to experiments both on myself and my patients, as follows: 1. A sensation of excitement; warmth through the whole body, especially in the face; oppression in breathing; and palpitation of heart in those not accustomed to mud-baths, which symptoms cease after about ten minutes, leaving merely a red tace and a feeling of heat at the vertex of the head; from the buttock and scrotum a vivid burning sensation extends up the extremities and back, with more or less tickling in various places. 2 . The first effect upon the pulse is an increase of from 10 to 12 beats per minute (in a novice of 16 per minute). During the remainder of the bath, it is true, this rate diminishes, but always remains from 4 to 8 beats higher than usual; two hours after the bath it is again regular. The number of respirations is also raised generally from 2 to 6 ; in the beginning still higher, but half an hour afterwards they become normal again. The more consistent the mud is, the clearer these effects. 3. The bodily heat, measured in the armpit, increased during a bath of half an hour by from $1.5^{\circ}$ to $35^{\circ} \mathrm{C}$. On bathing days the temperature of the body in the morning and evening has been greater by from $0.5^{\circ}$ to $1.3^{\circ} \mathrm{C}$. than usual. 4. The perspiration was more active immediately after the bath. The diuresis did not appear promoted after every mud-bath. The urates excreted in the urine were augmented by the mud-bath; the phosphates, however, diminished. 5 . The congestion of the head and the hyperæmia produced in very plethoric persons, as well as attacks of fainting or bleeding from the nose, are consequences of disturbance in the nerves and circulation, and the discharge appeared greatly increased when the baths were taken on the approach of menstruation.

On account of their general and special stimulating and animating effect on the skin these baths are used with benefit in the following affections:-1. Neurosis dependent upon anæmia or sexual derangements of women or upon spinal irritation; and in neuralgia of one or more nerves and their branches when free from inflammation. 2, Paralysis of rheumatic and arthritic origin, especially if caused by exudation on the periphery of the nerves, where it is intended to promote resorption and to restore interrupted innervation, as in anæmic women after difficult confinement; puerperal disesses, especially when an exudat remsined in the pelvis ; in hysteric paraly sis and that caused by cold in the lower extremities, or after sudden suppression of the catamenia in weak persons. All pressure on the nerves from rheumatic and gouty deposits is relieved by the mud-baths. In paralysis from apoplexy they also appear useful, but great precaution is necessary in cases inclined to congestion. 3. Chronic rheumatism of the muscles and joints when increased action of the skin is required. 4. Gout, because the mud-baths produce absorption of all swellings and local deposits around and within the joints, so that contractions and pseudo-ankylosis disappear, and there is increased change of matter, which promotes healthy nutrition. 5. Sexual derangements of females, when accompanied by anæmia or chlorosis, as in chronic metritis, dysmenorrhœa, amenorrhoa, hysteralgia, and chronic catarrh of the vaginal and utering mucous membranes. 6. Pollutions, spermatorrhœa, and impotence, in consequence of loss of blood and flesh from exhausting diseases; extreme mental and bodily fatigue, as long as there are no organic alterations within the spinal marrow. 7. Abdominal complaints caused by abdominal obstruction, piles, and, moreover, by very frequent and debilitating hæmorrhages from piles, by swelling of the liver, in consequence of hyperæmia and infiltration of the lymphatic glands in scrofulosis 8. Chronic enlargement of the spleen after malarial infection. 9. Inflammatory deposits in the perit uneal cavity following an attack of peritychlitis, parametritis, and perimetritis. The mud-baths are in all these cases attended with splendid results. 